\title{
Lutz Raphael, La ciencia histórica en la era de los extremos. Teorías, métodos y tendencias desde 1900 hasta la actualidad. Zaragoza: Institución Fernando el Católico, 2012. Traducción de Toni Morant Ariño, presentación Miquel Á. Marín Gelabert, 326 págs.
}

En la presentación a La ciencia histórica en la era de los extremos, Marín Gelabert asegura que esta obra es la mejor síntesis escrita sobre la historia de la historiografía del siglo XX. Después de una cuidada lectura, semejante aseveración quizá parezca demasiado aventurada. Sin embargo, lo que es seguro es que el libro que tenemos entre las manos es una obra llena de erudición y definitivamente bendecida por el don de la concisión. Aunque no podemos decir que falten textos de similar ambición y calibre, como los de Georg Iggers, no parece descabellado decir que la mayoría de los libros publicados sobre este tema tienden a aparecer bajo el rígido formato exigido por asignaturas como las de “Tendencias historiográficas actuales”. Así las cosas, pocas veces se ha publicado una panorámica sobre la historia de la profesión que aliente más allá de lo que tal asignatura ha venido exigiendo, o que nos invite a pensar la historiografía como una rama más de la producción cultural total de una época. Si bien Lutz Raphael no logra - ni lo pretende salirse del esquema trazado por la tradición historiográfica a la que pertenece, sí que permite una relectura tan abundante en sugerencias reflexivas sobre el lugar de la producción historiográfica como útil y orientativa para el estudiante de esta asignatura académica cuya enseñanza, como apunta el propio autor, ha sido el caldo de cultivo de este libro (p. 23).

En su acertada presentación, Marín Gelabert nos informa acerca de la tradición en la que Lutz Raphael (Essen, 1955) se entiende como historiador. La historia de la historiografía alemana no necesita presentación. A pesar de las diferencias existentes entre ellos, autores como Georg Iggers primero, o Jörn Rüsen después, son hoy dos de las principales referencias internacionales sobre el pasado de la profesión de historiador. Y ambos pertenecen a una historia de la historiografía germana tan potente como asentada. En una segunda generación, Lutz Raphael, como Christoph Cornelissen entre otros, se mueven dentro de esta misma tradición disciplinar. Raphael, en cambio, suma a este bagaje otro acerbo que refuerza al primero. Se trata del estudio de la construcción del Estado-nación contemporáneo.

Efectivamente, La ciencia histórica en la era de los extremos es, como apunta Marín Gelabert, una historia de la profesión (p. 21). Pero una historia del oficio que forma parte de la construcción y el devenir del Estado nacional contemporáneo. Y es que para Raphael la profesión de historiador y la construcción del Estado-nación son dos procesos que no pueden entenderse por separado. Nación y oficio de historiador son los dos pilares sobre los que va a levantar el resto de su estructura. 
El libro se divide en quince capítulos. Los tres primeros constituyen el planteamiento teórico desde el cual Raphael analiza el periodo. En ellos despliega las marcas de su formación alemana a la que añade una peculiaridad que tanto Rüsen como Iggers han venido también mostrando últimamente. Hablamos de un acendrado interés por la perspectiva global de la historia de la historiografía. Si nación y oficio son dos palabras clave para la edificación del proyecto, internacionalización - o globalidad - es el horizonte al que se dirige esta mirada. Aunque su silencio sobre Latinoamérica es doloroso, Raphael escribe con la misma solvencia sobre la historiografía soviética, japonesa o húngara que sobre la alemana. Ciertamente, su conocimiento no llega a todos los terrenos, insuficiencia que la historia global trata de solventar mediante proyectos de autoría colectiva. Pero el intento es encomiable y el resultado no es, ni mucho menos, indecoroso.

El resto de los capítulos, hasta el número XV, en el que Raphael se permite expresar tanto lo que él cree ver como tendencias y lo que espera como deseos, sigue más o menos la periodización tradicional de este tipo de obra. Pero lo hace focalizando sobre la evolución de las disciplinas y sub-disciplinas, más que sobre las tendencias generales. Con ello se permite una caracterización muy pormenorizada de áreas como la historia intelectual, la historia social, la historia de las ideas, o la historia de las relaciones internacionales. Sin perder de vista la división que Georg Iggers estableció para el siglo XX, Raphael lleva un paso más allá esta aventura. La individualización de cada sub-disciplina no queda difuminada dentro de las tendencias que Iggers identificó como mayoritarias en cada momento. Hay un tratamiento muy cuidado según el país y el área de investigación que viene a completar unos trabajos previos cuya principal - y necesaria - misión fue la de establecer la periodización de la producción historiográfica. El resultado es una obra más poliédrica, por un lado, y mucho más atenta al marco específico de la producción histórica académica. Es, en definitiva, una historia del oficio de historiador dentro de una perspectiva global.

Esto no se debiera achacar solo a un refinamiento de la tradición alemana que el propio Iggers, en una academia estadounidense poco proclive a la historia de la historiografía, había tendido a relajar. Si la perspectiva de Raphael se pretende global, la clave de bóveda de este proyecto es el concepto de autonomía científica. Efectivamente, esta es una historia de la profesión. El oficio nace con la construcción nacional, pero al mismo tiempo lo hace de una manera autónoma. La autonomía, siempre amenazada por el espectro del control político o la servidumbre nacionalista, ha sido víctima de un heterónomo siglo XX (p. 269). La historia de la profesión demuestra que cuando la autonomía de la historia ha sido más grande, la capacidad de la historiografía para generar beneficios para el conjunto de la humanidad ha sido mayor. Las democracias occidentales y la historiografía que les es propia, no sin que existan conflictos, parecen ser para Raphael las formas adecuadas de representación política e histórica. ${ }^{1}$

\footnotetext{
${ }^{1}$ En un punto esta lectura resulta claramente insuficiente cuando, apoyándose en Peter Novick, asume que la historiografía estadounidense del consenso era metodológicamente abierta y políticamente liberal. La propensión a usar el término liberal como un adjetivo que certifica la bonhomía de alguien o de algo debiera ser puesta en cuarentena, por lo que deberíamos empezar a considerarla una elocuente declaración de ISSN 2174-4289 
Ahora bien, sin querer enmendar esta conclusión que puede extraerse de la obra, percibimos aquí una ausencia que amenaza con tomar consecuencias lacerantes. Al intentar dar cuenta personalizada de cada tendencia y sub-disciplina dentro de la profesión, Raphael parece perder de vista algo importante. No es el contexto social y cultural, al que se refiere con frecuencia y al que maneja con insuperable soltura. Se trata más bien de lo que podríamos llamar política de la historiografía. Es decir, de un análisis más abierto a los efectos que para el lector - o para el productor en tanto que lector - tiene ese tipo de historia. Una perspectiva dialéctica que hubiese exigido, en primer lugar, la problematización del concepto de autonomía. En su lugar, este equívoco y esencialista concepto, como bien analizó Peter Bürger para el arte, se convierte en una clave de bóveda porosa que amenaza con derribar el resto de lo que es, en definitiva, un magnífico edificio.

Por la misma razón parece olvidarse las específicas trazas de clase que se pueden rastrear en este proceso. Lo heterónomo no es la intromisión nacionalista o dictatorial en la autonomía esencial, sino que es la constitución de la disciplina misma, que como tal exigió una fuerte depuración social y cultural de miradas alternativas. ${ }^{2}$ Omisión que también se percibe en el tratamiento, decididamente alemán, que Raphael da a la posmodernidad. Si bien la valoración es ambivalente, propia de un historiador que certifica hechos pero ante los que muestra cierta desconfianza, los confusos escritos de Habermas y Wellmer sobre el tema parecen sobrevolar el horizonte. La diferencia que establece entre antropología histórica, nueva historia cultural y posmodernismo parece insuficiente. Quizá porque, como en los autores antes citados, la diferenciación entre posmodernidad y posmodernismo es algo que no parece estar muy claro. Estos son, en definitiva, los aspectos más negativos del libro de Raphael: aquello que le otorga una visión particular sobre la historia de la historiografía es precisamente aquello que parece cegarlo en otros puntos de vista. La respuesta, como apuntó Fredric Jameson, quizá sea la implacable historización de todo elemento, incluido el decimonónico concepto de autonomía.

Para ir concluyendo, no quisiéramos dar la impresión con estas dos críticas que el libro es simplemente una correcta panorámica. Al contrario. Es también una necesaria corrección de anteriores y caducos puntos de vista que contiene hallazgos importantes. La relación que Raphael establece entre la estructura teórica marxista ortodoxa y la teoría de la modernización es reveladora de su capacidad para establecer iluminadoras conexiones entre diferentes sub-disciplinas (pp. 222-223, 247). No queda duda de la capacidad del autor para ello. Como no puede quedar duda alguna de la robustez de la tradición a la que pertenece. Más allá de las insuficiencias que hemos podido detectar, los objetivos parecen cumplidos en La ciencia histórica en la era de los extremos. Lutz Raphael nos regala una perspectiva

afiliación política. Referirnos a la historia del consenso como una etapa de feliz y abierto debate académico es un deseo no exento de cierta nostalgia académica que revela un tipo de ceguera muy particular (p. 278).

${ }^{2}$ A este respecto, no podemos dejar de referirnos al pionero trabajo de Hayden White, "The Politics of Historical Interpretation: Discipline and De-Sublimation,” Critical Inquiry, [vol.] 9, 1 (1982): 113-137. Lamentablemente, Hayden White no aparece ni una sola vez en toda la obra. Semejante ausencia en una síntesis internacional nos parece inexplicable.

ISSN 2174-4289 
global de la historia de la historiografía con la confianza de que el diálogo cultural internacional dentro de la profesión lleve a la completa desmitificación del eurocentrismo y el nacionalismo. Para Raphael esto es tanto un deseo como una tendencia real, no exenta de cambios bruscos de dirección y parones abruptos. Han pasado diez años desde su publicación original y el libro no ha perdido vigencia. Quizá, después de todo, sea cierto que es la mejor síntesis sobre tan inabarcable campo de estudio.

Miguel Ángel Sanz Loroño

Universidad de Zaragoza (España)

sanzlor@unizar.es

Fecha de recepción: 3 de junio de 2013

Fecha de aceptación: 8 de junio de 2013

Publicado: 15 de junio de 2013

Para citar: Miguel Ángel Sanz Loroño, "Lutz Raphael, La ciencia histórica en la era de los extremos. Teorías, métodos y tendencias desde 1900 hasta la actualidad. Zaragoza: Institución Fernando el Católico, 2012. Traducción de Toni Morant Ariño, presentación Miquel À. Marín Gelabert, 326 págs.”, Historiografías, 5 (enero-junio, 2013): pp. 128-131,

http://www.unizar.es/historiografias/historiografias/numeros/5/sanz_res.pdf 